\title{
Disagreement, Error and Two Senses of Incompatibility - The Relational Function of Discursive Updating
}

\author{
Tanja Pritzlaff \\ email: t.pritzlaff@zes.uni-bremen.de \\ webpage: http://www.zes.uni-bremen.de/homepages/pritzlaff/index.php \\ University of Bremen, Centre for Social Policy Research, Division 'Theory and Constitution of \\ the Welfare State', Parkallee 39, 28209 Bremen, Germany
}

\begin{abstract}
In Between Saying and Doing: Towards an Analytic Pragmatism, Robert B. Brandom puts forward a general method of formally representing relations between meaning and use (between vocabularies and practices-or-abilities) and shows how discursive intentionality can be understood as a pragmatically mediated semantic relation. In this context, the activity that pragmatically mediates the semantic relations characteristic of discursive intentionality is specified as a practice of discursive updating - a practice of rectifying commitments and removing incompatibilities. The aim of the paper is to take a closer look at the practice of discursive updating and to show that the inconsistencies, errors and failures in discursive practice that form the basis for the described update function can only be fully understood against the background of an agent's membership in the discursive community - i.e. if one looks at the explicitly social role of discursive updating.
\end{abstract}

\section{Introduction}

The aim of the following remarks is to take a closer look at the functional role of discursive updating - as presented especially in chapter 6 of Between Saying and Doing - and to further elaborate Robert Brandom's conception of discursive updating by assigning an explicitly social role in interactions with other agents to it.

As Brandom outlines in Between Saying and Doing and in a recent interview as well, inconsistencies, errors and failures in discursive practice can be described as a basis for an update function in the evolving structure of discursive practices. As Brandom puts it, the "role of disagreement and error, in particular the role of finding ourselves with commitments that are incompatible by our own lights, is an absolutely essential feature of the intelligibility of what we are doing, constraining ourselves by norms, that is, making ourselves subject to normative appraisal as to the goodness of our reasons for believing what we believe and for doing what we do. The principal motor of conceptual development is finding ourselves with incompatible commitments and acknowledging in practice the obligation to change something, so as to remove that incompatibility" (Pritzlaff/Brandom 2008, p. 375).

Following Brandom's conception, cases of disagreement and error involve two different kinds incompatibility. They involve incompatibility in the modal sense, i.e. that 
it is impossible for one and the same object in the world to have two materially incompatible properties, and they involve incompatibilities in the normative sense, i.e. that one cannot be entitled to two commitments that are incompatible in the light of the practices and attitudes of an agent, of the norms implicit in an agent's behavior. In Brandom's conception, these two kinds of incompatibilities are answered by practices of commitment revision that integrate the subjective perspective (that focuses on the knowing and acting subjects) and the objective perspective (that focuses on the objects and state of affairs in the world), corresponding to "the subjective and objective poles of the intentional nexus between what discursive practitioners $d o$, their activity of claiming, and the objects, properties, and facts that they thereby count as saying something about" (Brandom 2008, p. 200).

In expanding Brandom's conception of discursive updating by assigning an explicitly social role - in interactions with other agents and by explicit references to external authorities and social norms - to it, the paper also aims at a critical view on Brandom's claim that "the activity of taking or treating two commitments to be incompatible in the subjective normative sense just is what it is to take or treat two properties or states of affairs as incompatible in the objective modal sense" (ibid.).

\section{The Practice of Discursive Updating}

In chapter three of Between Saying and Doing, Brandom discusses arguments against two versions of AI-functionalism: Against the plausibility of the claims of the intellectualist program of classic symbolic AI, i.e. to understand knowing how to do something in terms of that something is true; and against the pragmatist thesis of a pragmatic version of $\mathrm{AI}$, a thesis about understanding knowing or believing that in terms of knowing how. His argument against this second version of AI - what he calls the "substantive practical algorithmic decomposability version of AI" (Brandom 2008, p. 78) - aims to show that all autonomous discursive practices exhibit some aspect that is "not algorithmically decomposable into non-discursive practices-or-abilities" (ibid., 79). ${ }^{1}$ In this context, the functional role of discursive updating is introduced.

For Brandom, the aspect of autonomous discursive practices that is not algorithmically decomposable into non-discursive practices-or-abilities is "the practice of doxastic updating - of adjusting one's other beliefs in response to a change of belief, paradigmatically the addition of a new belief" (ibid.). The reason why the decomposition is not possible is to be found in a characteristic of discursive updating that can be described as a kind of context sensitivity. The updating process is, as Brandom puts it, "highly sensitive to collateral commitments or beliefs" (ibid., 80). The significance of undertaking a new commitment depends not only on the content of that particular commitment. The significance of a new commitment stems from its interrelations within a network of other commitments an agent has already undertaken. To understand what a bit of vocabulary means can be characterized as knowing what difference the undertaking of that commitment would make "to what else the one using it is committed and entitled to" (ibid., 79). The addition of a new belief to an already ex-

1 "That would be something that is PV-necessary for deploying any autonomous vocabulary (or equivalently, PP-necessary for any ADP) that cannot be algorithmically decomposed into practices for which no ADP is PP-necessary" (ibid.). 
isting web or network of related commitments and entitlements requires the mastery of a practice that updates the whole set, a practice that reassigns the meaning and significance of the other, already existing elements in the light of the new belief as well. Being able to perform this practice includes being able to distinguish which further commitments would and which would not infirm or defeat an undertaken commitment, i.e. the ability to "associate with each commitment a range of counterfactual robustness". This means that one must not only be able to identify claims that are incompatible with the new additional commitment, but claims that are incompatible with it only in the context of one's other collateral beliefs, i.e. claims that are "contextually incompatible" with it (ibid., 80).

For Brandom, the global updating ability exhibited in the performance of this practice is an ability that cannot be assigned to non-discursive creatures. Doxastic updating requires that in the light of new information, language users are able to distinguish between information that is and information that is not relevant to the claims and inferences one endorses. Since any new information about an object carries with it new information of some kind about every other object, and any change in any property of one object changes some of the relational properties of all other objects, language users have to be able to separate contextually relevant from contextually irrelevant information. Or, as Brandom puts it: The crucially important cognitive skill that is needed to perform the practice of doxastic updating is the capacity "to ignore some factors one is capable of attending to" (ibid., p. 81); and the defining feature of that skill is displayed by the ability to decide what to ignore. As competent language users we are able to decide which aspects of a new bit of information are relevant or significant in the context of claims about objects we are concerned with and to decide which complex relational properties we should ignore in our reasoning (ibid.).

\section{Two Senses of Incompatibility}

In chapter 6 of Between Saying and Doing, Brandom focuses on the semantic relations between words and the world. The use of words is not limited to constituting relations between vocabularies. To say something consists of talking about something in the world, about the objects or states of affairs that the words and sentences refer to or represent.

The argument developed in chapter 6 of Between Saying and Doing further elaborates the complex, pragmatically mediated semantic relations between normative and modal vocabularies introduced in chapter 4 and 5. Brandom claims in chapter 6 that the intimately related features of normative vocabulary and modal vocabulary correspond to the subjective and objective poles of intentional relations, "between what discursive practitioners $d o$, their activity of claiming, and the objects, properties, and facts that they thereby count as saying something about" (ibid., 200). While normative vocabulary "makes explicit important features of what knowing and acting subjects $d o$ when they deploy a vocabulary, when they use expressions so as to say something", modal vocabulary "makes explicit important features both of what is said and of the objective world that is talked about" (ibid., p. 181). Normative vocabulary and modal vocabulary both articulate discursive commitments. But while normative vocabulary "addresses in the first instance acts of committing oneself", modal vocabulary addresses "the contents one thereby commits oneself to" (ibid.), in the sense of 
"how one has committed oneself to the world being, how one has represented it as being" (ibid.).

In the course of this argument, Brandom differentiates between two - related senses of incompatibility: an objective modal sense of incompatibility ("a matter of what states of affairs and properties of objects actually are incompatible with what others" (Brandom 2008, p. 191)) and a subjective normative sense (that concerns commitments on the part of knowing-and-acting subjects). Brandom's argument leads to the key point that by "engaging in the practice of rectifying commitments, subjects are at once both taking or treating the commitments involved as incompatible in the normative sense of obliging them to do something about that collision, and taking or treating two states of affairs regarding objects as incompatible in the modal sense that it is impossible for both to obtain" (ibid., p. 193). What is made explicit in the objective sense of incompatibility by modal vocabulary and in the subjective sense by deontic normative vocabulary are, as Brandom puts it, "essentially complementary aspects", "connecting knowing and acting subjects with the objects they know about and act on" (ibid., p. 196). Acknowledging material inferential and incompatibility relations among commitments, therefore, essentially involves a representational relation to objects, i.e. to facts in the world that one is talking about, and to laws relating possible facts.

In this context, practical intentionality, identified as the most fundamental kind of intentionality, is characterized as a directedness towards objects and a practical involvement with those objects exhibited by creatures dealing skillfully with the world. The most basic form of such activity consists of "an open-ended sequence of feedback-governed performances" (ibid., p. 178). And these feedback-governed processes function only insofar as they refer in some way to changes in the world - changes one responds to or changes that are induced by responses. Feedback loops of perceptionand-performance essentially involve "objects, events, and worldly states of affairs" (ibid., p. 178). Discursive intentionality is to be understood as a species of such feedback-governed practical engagement, as "a development of and a special case of" basic practical intentionality (ibid., p. 179). A creature exhibits specifically discursive intentionality insofar as its performances and ways of responding are mediated by relations of material inference and incompatibility. The directedness at objects characteristic of practical intentionality turns, as Brandom puts it, "into something intelligible as representation of those objects when the process of practical engagement takes the form of deontic updating structured by material inferential and incompatibility relations, that is, when it becomes discursive intentionality" (ibid., p. 184). And the two poles of discursive intentionality, "knowing and acting subjects and the objects they know of and act on, their representing activities and the objects and objective states of affairs they represent" (ibid., p. 179), can only be understood in the light of the semantic intentional relations they stand in one to another. For doing that, one must, as Brandom puts it, "start with an understanding of the thick, essentially worldinvolving practices engaged in and abilities exercised, and abstract from or dissect out of that an understanding of the two poles of the semantic intentional relations those practices and abilities institute or establish" (ibid., p. 179-180). This way to proceed is in accord with what Brandom refers to as the pragmatist order of semantic explanation. 
Discursive activity involves practical engagements with things, but also the "rational critical responsibility implicit in taking incompatible commitments to oblige one to do something" (ibid., p. 189). And this doing, required by the incompatible observational commitments in the world as well as by the normative obligation to do something about the incompatibility of one's own commitments, is the practice of discursive updating. While the first aspect becomes apparent in a modal notion, i.e. that it is impossible for an object to be made of pure copper and to be an electrical insulator at the same time, the second aspect is associated with the practices and attitudes of the subjects engaged in discursive practices. It is a matter of the "norms implicit in their behavior, what they in practice take or treat as incompatible in acknowledging and attributing the deontic statuses of commitment and entitlement" (ibid., p. 191). The practice of discursive updating, therefore, functions in two senses as a way of noting and repairing incompatibilities. It is a response to two different kinds of incompatibilities, although these two senses or kinds are, as Brandom puts it, "related in a surprising and revealing way" (ibid., 190-191).

In an objective modal sense, it responds to "what states of affairs and properties of objects actually are incompatible with what others, in the world as it is independent of the attitudes of the knowing-and-acting subjects of practical, feedback-governed transactional engagements" (ibid., p.191). In the normative sense, discursive updating aims, as Brandom puts it, at "the material inferential completeness and compatibility of one's commitments, in the normative sense that insofar as one falls short of those ideals, one is normatively obliged to $d o$ something about it, to repair the failure" (ibid., p. 187).

\section{The Social Role of Discursive Updating}

Within the process of commitment revision as described by Brandom, the relational function of discursive updating is of vital importance. But while it seems clear that the need to update one's commitment in the light of the two senses of incompatibility as described above is not a merely individual, but also a social requirement, Brandom doesn't go into details on how a practice of discursive updating actually functions within the social sphere. And although a parallel between the way in which an individual subject deals with incompatible commitments and the way a community deals with incompatible commitments seems to exist, it doesn't become clear how an updating practice may function in cases in which different subjects within a community contradict each other, disagree about properties of facts in the world or about how to proceed when faced with, for example, diverging external norms or authorities they refer to in trying to resolve a conflict. The kind of normativity exhibited in these cases seems to be not only a kind of in-process, but a kind of interpersonally established normativity. The question that follows from this is: In which sense is finding ourselves with commitments that are not incompatible by our own lights, but are incompatible in the light of other members of our community an essential feature of what we are doing? If finding ourselves with incompatible commitments and acknowledging in practice the obligation to change something, so as to remove that incompatibility, is the principal motor of conceptual development, wouldn't it be possible to say that finding ourselves and our own commitments in conflict with the commitments of 
others is a principal motor of, for example, the development of social or political norms? $?^{2}$

As Raffaela Giovagnoli points out, discursive updating functions in cases and contexts of conflict - not only in the subjective, but also in the social sphere. In interaction with other agents, we get into contact with points of view different from our own (Giovagnoli 2007, p. 93). Following Giovagnoli's line of argumentation, the relational function of discursive updating as characterized by Brandom can be further elaborated, focusing on the critical dimension of its social role in practices that can be understood as social practices in the narrower sense of the word, i.e. as interactions with other agents. Social practices in this sense can be described as feedbackgoverned, as „complex patterns of mutual responsiveness“ (Rouse 2007, p. 52), embedded in a structure of "default" and "challenge" of the commitments and entitlements of different agents (Giovagnoli 2007, p. 85). In the social sphere of interaction with other agents, performances respond to one another through acts of correction and repair, through acts of translation, feedback loops, reward or punishment of a performer, by trying to replicate an act in different circumstances, mimicking it, and so on (Rouse 2007, p. 49). In the game of giving and asking for reasons, agents appeal to external authorities (Giovagnoli 2007, p. 83) to defend their claims, and update their beliefs not only about objective facts in the world (for example about the properties of copper (Brandom 2004, p. 250)), but also about normative facts (Brandom 2000a), for example about legal terms (Klatt 2008).

Inconsistencies, errors and failures in discursive practice that form the basis for the described update function can only be fully understood against the background of an agent's membership in the discursive community (Kukla/Lance 2009, p. 190-195), i.e. if one looks at the explicitly social role of discursive updating.

Discursive practices are characterized by Brandom as special cases and developments of feedback-governed, 'thick' practices - 'thick' in the sense of "essentially involving objects, events, and worldly states of affairs" (ibid., p. 178). They function successfully if objective facts about what actually follows from and is incompatible with what are incorporated in the "material inferences and incompatibilities that articulate the concepts expressed by the vocabulary deployed according to the practical norms implicit in that practice. This essentially holistic process involves getting on to how things objectively are not just by making true claims, but also by acknowledging the right concepts" (ibid., p. 186). Even if one assumes that "the how things are is allowed to have normative significance for the correctness of someone's sayings and believings only in the context of someone else's attitudes towards how things are" (Brandom 2000b, p. 165), that is that they are filtered through the takings-true of the one assessing a claim, the central feature of a successful discursive practice seems to be its relation to facts in the world. And even if one assumes that the facts are "caught up in social practices by being endorsed by the one attributing knowledge", so that the picture doesn't contain a kind of "contact between naked, unconceptualized reality and someone's application of concepts" (ibid.), skepticism about the normative word-

\footnotetext{
${ }^{2}$ Brandom himself draws an analogy between conceptual norms and political norms in Brandom 1979.
} 
world relations implied in this conception of discursive practices seems to remain. ${ }^{3}$ At least, it seems to be a crucial point how a kind of "triangulation" (Brandom 2008: 188) on an object in the world would look like that involved the differing commitments of different subjects. The missing link in this picture of a social version of the practice of discursive updating seems to be an elaborate conception of how performances of different subjects respond to one another in a dynamic context of interaction.

\section{Conclusion}

The aim of the paper has been to take a closer look at the practice of discursive updating and to present some - although very preliminary - ideas about how the functional role of this practice might be interpreted in the light of inconsistencies, errors and failures occurring in the interaction of different agents. If one looks at the explicitly social role of discursive updating, the centrality of the relation to objects in the world - the feedback-governed aspect of the practice, characterized by essentially involving objects, events, and worldly states of affairs - seems to be problematic. The relation that needs to be focused on when thinking about discursive updating in a social sense seems to be the relation between the differing, conflicting commitments undertaken by different subjects within a community and the ways in which these differing, conflicting commitments are exhibited by performances that respond to one another in a dynamic contexts.

\section{References}

Brandom, R. B. (1979) "Freedom and Constraint by Norms", American Philosophical Quarterly, 16 (3), pp. 187-196.

Brandom, R. B. (1994) Making it Explicit. Reasoning, Representing, and Discursive Commitment, Cambridge, MA/London: Harvard University Press.

Brandom, R. B. (2000a) "Facts, Norms, and Normative Facts: A Reply to Habermas", European Journal of Philosophy, 8 (3), pp. 356-374.

Brandom, R. B. (2000b) "Vocabularies of Pragmatism: Synthesizing Naturalism and Historicism", in: Rorty and his Critics, Robert B. Brandom (ed.), Malden, MA: Blackwell, pp. 156-183.

Brandom, Robert B. 2004: "From a Critique of Cognitive Internalism to a Conception of Objective Spirit: Reflections on Descombes' Anthropological Holism”, Inquiry, 47 (3), pp. 236-253.

Brandom, R. B. (2008) Between Saying and Doing. Towards an Analytic Pragmatism, Oxford/New York: Oxford University Press.

Giovagnoli, R. (2007) Autonomy: A Matter of Content, Firenze: Firenze University Press.

Klatt, M. (2008) Making the Law Explicit. The Normativity of Legal Argumentation, Oxford/Portland, OR: Hart Publishing.

${ }^{3}$ This skepticism also applies to the conception of representation as presented already in the second part of Making it Explicit (Brandom 1994). 
Kukla, R./Lance, M. (2009) 'Yo!' and 'Lo!'. The Pragmatic Topography of the Space of Reasons, Cambridge, MA/London: Harvard University Press.

Pritzlaff, T./Brandom, R. B. (2008) "Freedom is a Matter of Responsibility and Authority. An Interview with Robert B. Brandom", European Journal of Political Theory, 7 (3), pp. 365-381.

Rouse, J. (2007) "Social Practices and Normativity", Philosophy of the Social Sciences, 37 (1), pp. 46-56. 